\title{
Research on Coordination Relationship between Ecological Environment and Urbanization in Kunming Based on Coupling Model
}

\author{
Chunhong Xia, Yan Li, and Ruiliang Li
}

\begin{abstract}
Along with the process of globalization, how to coordinate the development of urbanization and ecological environment has become an important issue for the current academic circles. Kunming is located in the southwestern part of China and belongs to the plateau lakeside city and the ecological environment is fragile. Taking the data of urbanization and ecological construction in Kunming from 2007 to 2016 as a sample, this paper designs the Kunming urbanization and ecological environment evaluation index system based on the situation of Kunming City, and adopts the entropy weight method and the linear weighting method to evaluate the urbanization of Kunming. The research results show that the urbanization process of Kunming City climbed up, indicating that Kunming's urban construction achievements were remarkable from 2007 to 2016. However, the ecological environment of Kunming is not optimistic, showing a fluctuating trend. The coordination degree between the two systems has experienced three stages of antagonism, integration and coordination. How to protect the ecological environments has become a key issue that must be faced and solved in the current urban development of Kunming.
\end{abstract}

Index Terms-Kunming city, urbanization, ecological environment, coordination.

\section{INTRODUCTION}

In recent years, with the development of the global economy, China's urbanization has entered a stage of rapid development. According to official Chinese statistics, China's urbanization rate rose from $17.6 \%$ in 1978 to $57.35 \%$ in 2016 [1]. However, urban ecological environment issues are also becoming increasingly prominent. Haze, water pollution, and the greenhouse effect have become "epidemic diseases" in today's cities. How to coordinate the relationship between urbanization and ecological environment has become a hot issue in the global academic community.

As far as foreign research is concerned, the focus on the coordinated development of the two originated after the industrial revolution. In the middle of the 20th century, London, England, once became a "fog capital", the quality of those urban living environment declined, and many residents there were sick. Therefore, in this social context, people

Manuscript received October 7, 2018; revised April 14, 2019. This work was supported in part by the Yunnan University's Research Innovation Fund for Graduate under Grant No.2018z039 and Yunnan Provincial Science and Technology Department for Graduate in China.

The authors are with the School of Architecture and Urban Planning, Yunnan University, Kunming, CO 650500 China (corresponding author: Yan Li; e-mail: RitaXCH@163.com, Leeyan5@163.com, 1346425267@qq.com). began to change their mindset, instead of pursuing the one-sided growth of the urban economy in the past, but calmly re-examining the urban environment in which they live, thinking about and exploring urbanization and ecological environment. The relationship between. In the Ebenezer Howard's book, Tomorrow, a Path to Peace for Real Reform, the first to propose the meaning of "idyllic city" is a city designed and built around the theme of health, life and industry [2]. In such a city, the urban residents who are the mainstay of the society can enjoy the idyllic scenery while enjoying the rich urban life. The essence of the city is the combination of urban and rural areas. To a certain extent, Howard's "Garden City" concept officially lifted the curtain on people's perception and exploration of the interaction between urbanization and ecological environment. Subsequently, American scholars Grossman and Kruege put forward to the Environmental Kuznets Curve (EKC) based on the logical relationship of Simon Kuznets' Kuznets curve. They believe that there is a "U"-type relationship between the degree of environmental pollution and per capita income as the per capita income increases, the degree of urban environmental pollution increases [3]. When the per capita income reaches a certain level, the degree of environmental pollution will gradually decline. According to the EKC theory, in a city and even the whole country in the process of urbanization, the old road of urban development with "first pollution and governance" is inevitable. Iwata. $\mathrm{H}$ and Okada. $\mathrm{K}$ et al, by constructing an autoregressive distribution lag model, combined with EKC theory to study the relationship between $\mathrm{CO}_{2}$ emissions and economic development in France, and conclude that in the middle of urbanization in developed countries, people can't avoid urban environmental pollution. Only when the country's overall economy and per capita income reach a certain level, the whole society will begin to promote ecological governance [4], which verifies the existence and rationality of EKC theory. At the same time, along with the deepening of the concept of global sustainable development, foreign scholars began to study the interaction between urbanization and ecological environment from different perspectives, and proposed new ideas that keep pace with the times. For example, Zhongjie Lin, a scholar at the University of Pennsylvania, proposed ecocity urbanism by comparing the origins, policies, and measures of eco-city construction between China and Japan in the Asian region [5]; J. Jorge Ochoa thinks, by analyzing the successful construction of 185 cities around the world under the guidance of the theory of sustainable development, it is clearly pointed out that community participation, urban 
volume, education and work innovation and other factors play an important role in urbanization and ecological environmental protection [6].

China's research on the relationship between urbanization and ecological environment started late. In the early 1980s, Chinese ecologists Ma Shijun and Wang Rusong proposed the urban complex ecosystem theory on the basis of summarizing ecological control theory [7]. It is clearly pointed out that the essence of sustainable development is the coordinated development between human-centered life and its habitation environment, material production environment and social and cultural environment. With the deepening of the national emphasis on the ecological environment and the development of sustainable development practices, cities have successively proposed urban development themes such as "ecological civilized cities", "low carbon cities", "green cities" and "resilient cities" [8]-[10]. At the same time, the new urbanization construction achieves the goal of respecting nature, protecting the environment, and achieving harmonious coexistence between man and nature. At the beginning of the 21 st century, scholars such as ecology and sociology successively cited the coupling model to quantitatively analyze their coordination relationship [11]-[14]. This article combines "urbanization", "ecological environment" and "coupling relationship" as three key words. Through the cnki.net platform search, as of July 30, 2018, there are 94 related journals and 13 masters. The paper studies the coupling relationship between Ecological Environment and Urbanization in Kunming. Through the quantitative treatment of the two types of primary indicators of urbanization and ecological environment, the urbanization and ecological environment relationship of a certain city or region are systematically evaluated objectively. For example, using the coupled model to analyze the eco-economic coordination degree of Chengdu-Chongqing urban agglomeration [15]; based on the mechanism of system coupling, empirically study the relationship between tourism in Xinjiang, new urbanization and ecological environment in 2006 [16]; using the coupling model to calculate the coordination degree of urban land intensive and ecological environment in China [17].

As mentioned above, the research on the relationship between urbanization and ecological environment at home and abroad has gradually changed from a single qualitative research to a comprehensive study combining qualitative and quantitative, showing a diversified research trend. However, its focus is mainly on the coordinated development of urbanization and ecological environment at the macro level, ignoring the heterogeneity of the various elements between urbanization and ecological environment within the region. Therefore, we made an in-depth analysis of the internal development mechanism of urbanization and ecological environment, the development of an evaluation index system according to local conditions, quantitative analysis of the relationship between the two through the existing and mature coupling model, the internal coupling law and the coercive constraint mechanism between the two. It is of great significance for the construction of "beautiful China" to carry out analysis and put forward practical suggestions and measures for the future urbanization and coordinated development of the ecological environment in the region.

\section{MATERIALS AND METHODS}

\section{A. Indexes System}

The selection of each factor indicator in the evaluation index system is related to the correctness of the whole system analysis and evaluation, which directly affects the later research results and the recommendations based on the results. Therefore, to correctly evaluate the construction of the indicator system, we need to follow the following principles: i) The principle of objectives, the selection of each indicator should be based on the research objectives, and should not deviate from the original intention of establishing indicators; ii) The principle of objectivity, the process of selecting indicators in the meantime, while ensuring the authenticity, authority and reliability of the indicator data source, it can also objectively reflect the real situation through indicators; iii) Scientific principles, indicators can not be selected out of thin air, should be based on scientific premise, avoid mixing personal factors; iv) Comprehensive principle, requiring each of the selected indicators to reflect a certain type of social development, while the selection of indicators should avoid duplication; v) The principle of accessibility of data, due to the focus of the content of the yearbooks in different regions and the difference is different from the economic and social development in different years in the same region, and the data types are also different. Therefore, when selecting indicators, it is necessary to ensure that the required time-space contrast indicator data can be obtained simultaneously. Similarly, when selecting the comprehensive evaluation indicators of urbanization and ecological environment, the above five principles should be strictly followed.

At present, the official indicator system for urbanization evaluation has not been unified. According to the domestic and international literatures on the construction of urbanization evaluation index system [18]-[20], we found that most studies have divided the urbanization into four first-level indicators: economic urbanization, population urbanization, social urbanization and spatial urbanization. Among them, the indicator of economic urbanization is the basis of the other three. The GDP per capita, the disposable income of urban residents, the proportion of secondary and tertiary industries to GDP, and the total retail sales of social consumer goods are used to reflect the urban economy, urban residents' income and overall consumption of a region. The population urbanization index mainly focuses on reflecting the employment situation of urban residents and the most intuitive expression of urbanization rate. The three sub-indicators of urban population proportion, non-agricultural employees and urban unemployment rate are selected respectively. Social urbanization indicators mainly refer to in the whole region, with the economic development, people began to pursue high-quality life, so we selected representative indicators to comprehensively reflect: the number of urban parks, car ownership, public book collection and number of health institutions; The space urbanization indicators closely reflect the changes brought about by 
urbanization around "space", so we selected urban construction land, per capita urban road area, urban population density and urban traffic mileage.

The PSR (Pressure-State-Response) model was first proposed by the Organization for Economic Co-operation and Development (OECD) in the 1990s and later developed by the European Environmental Agency (EEA). It has become one of the bases for judging environmental conditions and issues and an effective tool for causality. The model aims to conduct a multi-dimensional analysis of the relationship between ecological construction in a certain area and the overall environmental development prospects, ensuring that each stage can formulate policies that are consistent with the actual situation and measures that are easy to implement [21]. In this paper, based on the three criteria layers of Eco-Pressure, Eco-State and Eco-Response, 15 element layers are further subdivided, of which ecological stress is the main consideration. The amount of natural resource endowment, which is necessary for human production and life, is divided into the total amount of urban water resources, the total amount of urban gas supply (the total amount of urban liquefied gas gas supply and the total amount of urban artificial gas supply), the urban natural wetland area and urban crops. The planting area has 4 element layers; the ecological status mainly considers the environmental changes caused by human activities under the condition of limited resource stock and environmental carrying capacity, and is divided into the total amount of urban sewage discharge, the days of good urban air quality, and the per capita public green area, the amount of pesticides used and the amount of domestic garbage removal layer; The ecological response mainly focuses on the quantifiable positive indicators of government, society and individuals in environmental governance in the process of urbanization: total afforestation area (including Afforestation and aircraft planting area), investment in environmental protection, harmless treatment rate of domestic garbage, industrial fixed waste Rate, green rate built-up areas and urban sewage treatment rate.

\section{B. Standardization of Data}

The data will be by the extreme value method. The formula is:

Positive indicator standardization: $X_{i j}^{\prime}=\frac{X_{i j}-X_{i j \min }}{X_{i j \max }-X_{i j \min }}$

Negative indicator standardization: $\quad X_{i j}^{\prime}=\frac{X_{i j \max }-X_{i j}}{X_{i j \max }-X_{i j \min }}$

Among them, the standardized index value is the original value of the index. Positive indicators are equivalent to incentives, so the greater the value of the positive indicator, the better the result; the negative indicator is equivalent to the blocking effect, so the smaller the value of the negative indicator, the better.

\section{The Entropy Method}

There are some differences in the degree of influence of different indicators on the system. In order to reflect this difference, it is necessary to assign a certain weight to the evaluation indicators. The methods for determining the weight of the evaluation factor indicators mainly include objective assignment method and subjective assignment method. In order to avoid the influence of human factors and make the index weight determination more scientific, the entropy weight method in the objective weighting method is used to determine the index weight.

An overview of the entropy weighting method: In information theory, uncertainty is often used to measure uncertainty. Among them, the amount of information and entropy shows an inverse relationship, that is, the amount of information that people have mastered increases, the uncertainty decreases, and the entropy also decreases. Therefore, according to the above characteristics, the degree of dispersion of the index can be judged by the entropy value, that is, the greater the degree of dispersion of the index, the greater the influence (weight) of the index on the comprehensive evaluation. The specific calculation process is as follows:

Step 1: Calculate the proportion of index value of the nth item under the index:

If there are $\mathrm{j}$ items to be assessed and $\mathrm{i}$ evaluation indicators, the original evaluation matrix was formed. $\mathrm{R}=\left(X_{n m}\right)_{i j}$

$$
\text { Step 2: } P_{n m}=\frac{X_{n m}^{\prime}}{\sum_{n=1}^{j} X_{n m}^{\prime}}
$$

Calculate the entropy of the index $e_{m}$

$$
e_{m}=-k \sum_{n=1}^{j} P_{n m} \cdot \ln p_{n m}
$$

Step 3: calculate the entropy weight of the index $Z_{m}$

$$
Z_{m}=\left(1-e_{m}\right) / \sum_{n=1}^{i}\left(1-e_{j}\right)
$$

Finally, after determining the weight of each indicator of ecological construction in Kunming City, according to the linear weighted comprehensive scoring formula, the comprehensive score of ecological construction of Kunming City from 2007 to 2016 can be calculated:

$$
W=\sum_{i=1}^{n} W_{i j} X_{i j}^{\prime}
$$

Among them, $\mathrm{W}$ denotes the comprehensive score of ecological construction in Kunming every year, $W_{i j}$ denotes the weight of each index, and $X_{i j}^{\prime}$ denotes the index data of extreme value.

\section{The Coupling Coordination Degree Model}

\section{1) The coupling model}

The term "coupling" is derived from physics and is a measure used to quantify the degree of interdependence and interdependence between two or more objects. Coupling degree calculation formula:

$$
C=\left[\frac{W_{1} \times W_{2}}{\left(W_{1}+W_{2}\right)^{2}}\right]^{1 / 2}
$$


Among them, $W_{1}$ is the comprehensive score for urbanization. $W_{2}$ is the comprehensive score of the ecological environment, and $\mathrm{C}$ is the coupling value of the two systems, and its scope: $C \in[0,1]$

\section{2) The coupling coordination degree model}

Because the degree of coupling can only explain the relationship between urbanization and the ecological environment, and cannot show the degree of coordination and coordination between the two, it is necessary to introduce the coupling coordination degree model. On the one hand, the coupling coordination degree model can reflect the degree of interaction between the two; on the other hand, it reflects the level of coordinated development of the two. Coupling coordination degree calculation formula: $R=\sqrt{C \times T}, T=\alpha \times W_{1}+\beta \times W_{2}$

Among them, $\mathrm{R}$ is the coupling coordination degree, $\mathrm{T}$ is the inter-system comprehensive coordination index, and $\alpha$ and $\beta(\alpha+\beta=1)$ are the undetermined coefficients. In this paper, urbanization and ecological environment play an equally important role for any city in the process of sustainable development. So make it $\alpha=\beta=0.5$

\section{3) The coordination degree classification of coupling}

The coupling coordination degree model is used to reflect the coordinated development relationship between urbanization and ecological environment. After learning from the authoritative journal literatures [11], [20], [22] and consulting relevant experts, this paper divides the coupling degree of urbanization and ecological environment into sections as follows:

TABLE I: COUPLING COORDINATION DEGREE CLASSIFICATION STANDARDS

\begin{tabular}{ccc}
\hline \hline number & range & level \\
\hline 1 & $0.000-0.100$ & extreme antagonism \\
2 & $0.101-0.200$ & moderate antagonism \\
3 & $0.201-0.300$ & mild antagonism \\
\hline 4 & $0.301-0.400$ & slight the running-in period \\
5 & $0.401-0.500$ & mild the running-in period \\
6 & $0.501-0.600$ & moderate the running-in period \\
7 & $0.601-0.700$ & extreme the running-in period \\
\hline 8 & $0.701-0.800$ & mild coordination \\
9 & $0.801-0.900$ & moderate coordination \\
10 & $0.901-1.000$ & extreme coordination \\
\hline \hline
\end{tabular}

\section{EMPIRICAL ANALYSIS}

\section{A. Study Area}

Kunming is the capital of Yunnan Province, located in the central part of Yunnan Province. In the Kunming City Master Plan (2011-2020), Kunming has updated its urban development goals and tried to build Kunming into a gateway city facing China's southwest and important. As a regional national transportation and information hub Kunming has become a plateau lakeside ecological livable city that integrates historical humanities and natural scenery.
Therefore, the coordinated development of urbanization and ecological environment in Kunming plays a benchmark role in the construction of urban civilization in the province and is an important part of the construction of "Beautiful Yunnan".

\section{B. Data Source and Pre-processing}

Through the "Yunnan Province Yearbook", "Kunming Statistical Yearbook" and "Kunming Environmental Bulletin" (2007-2016), we reviewed the relevant data on urbanization and ecological environment to ensure the authority and reliability of the data source.

\section{Results}

\section{1) Index weight value of urbanization and ecological environment in Kunming}

Obtaining the required data by consulting the official yearbook and calculate the formula according to the entropy method (Table II).

TABLE II: INDICATOR WEIGHTS AND COMPREHENSIVE SCORES OF URBANIZATION AND ECOLOGICAL ENVIRONMENT

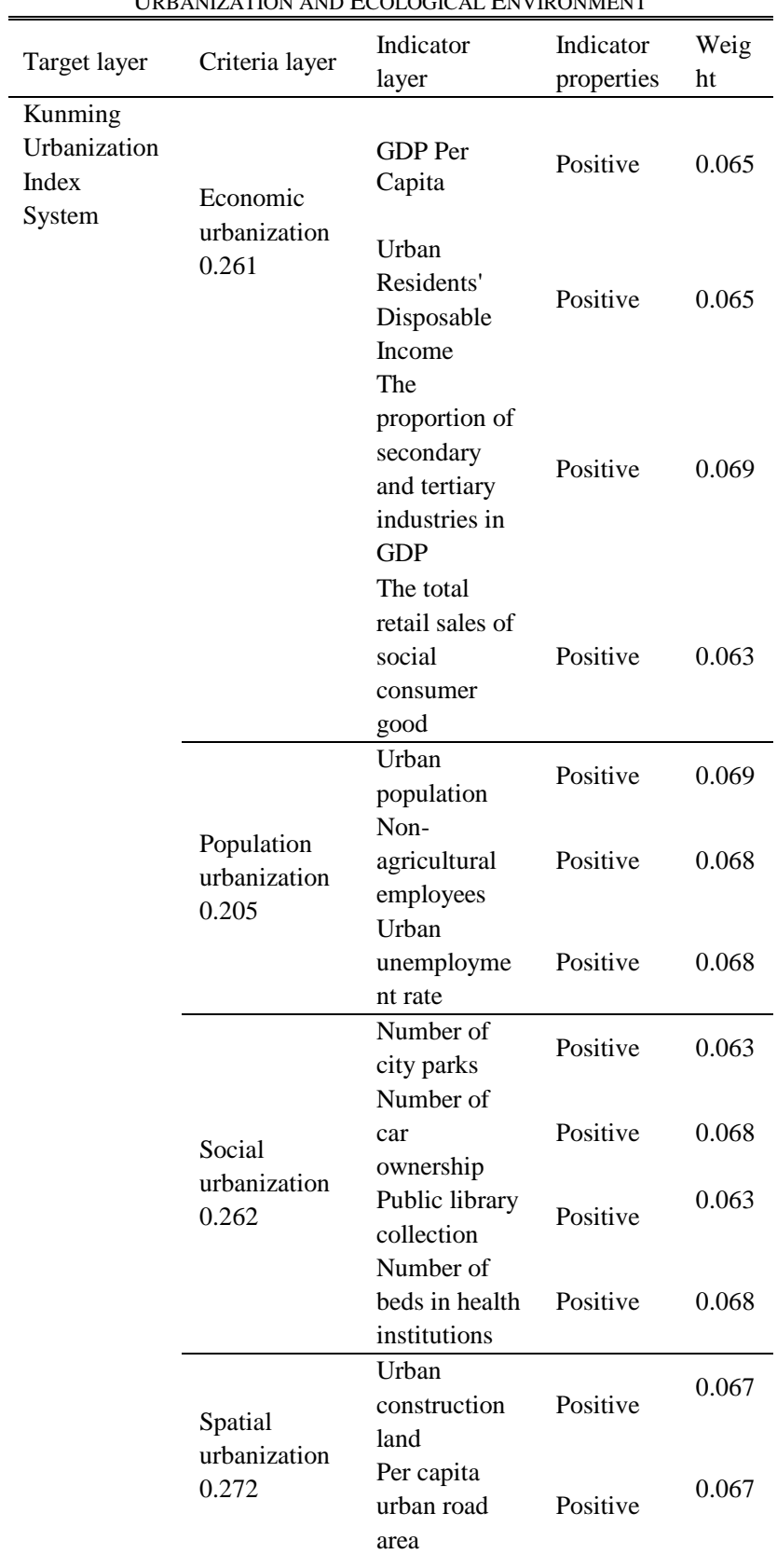




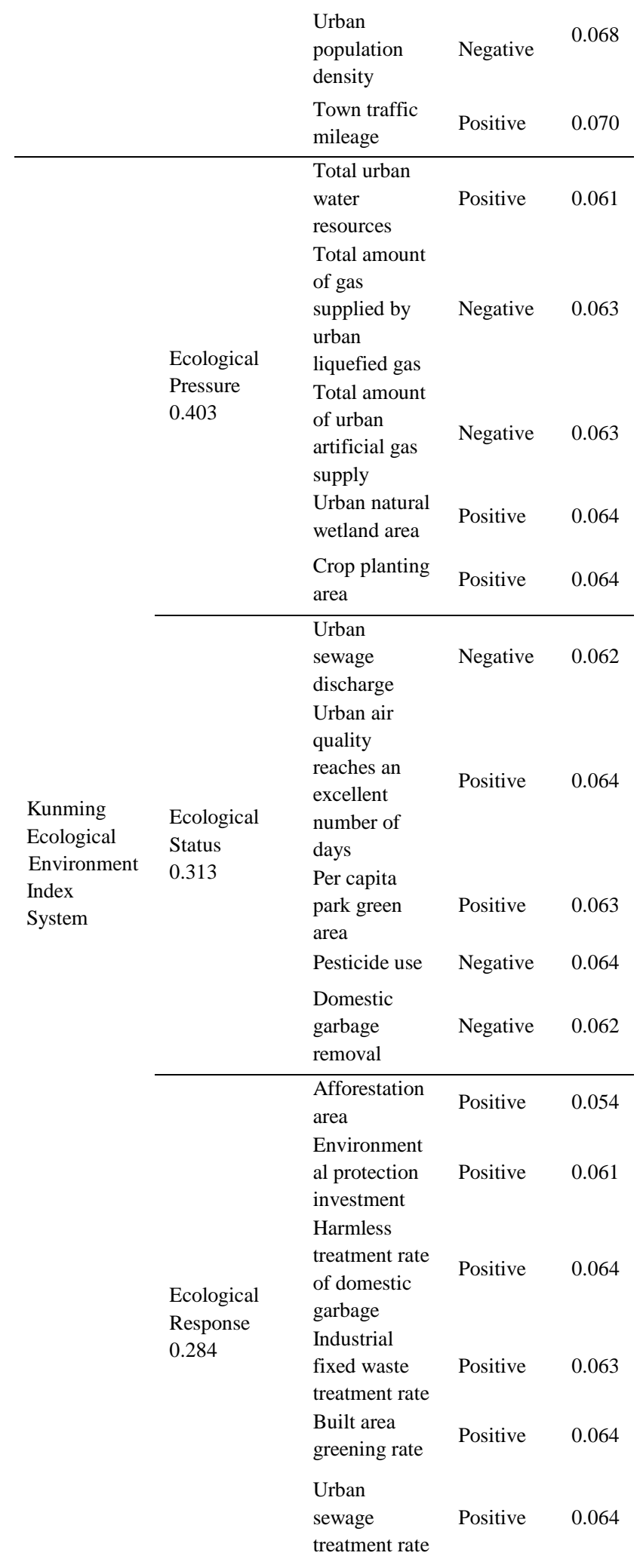

Note: This table is rounded to four digits after the decimal point, so the weights at the various levels deviate slightly from the actual values, but the actual values are used in the actual calculation.

2) Comprehensive score, coupling degree and coupling coordination degree of urbanization and ecological environment in Kunming

According to the above linear weighting method and the calculation formula of the coupled model, the comprehensive scores of urbanization and ecological environment of Kunming City and the coupling and development stages of 10 time nodes from 2007 to 2016 are obtained (Fig. 1).

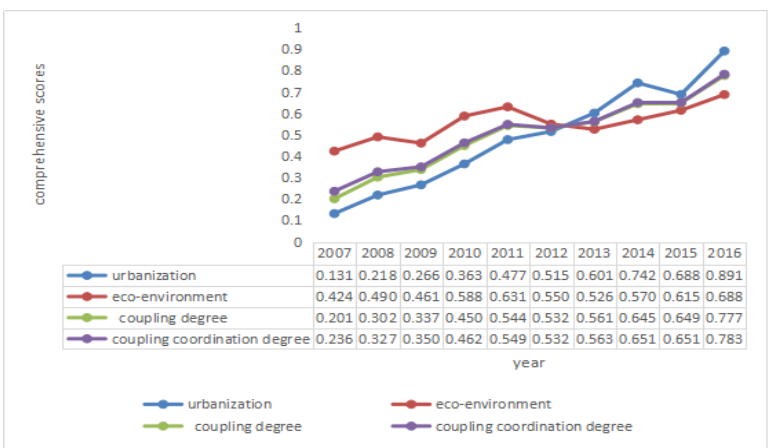

Fig. 1. Coupling coordination degree of urbanization and eco-environment.

\section{Analysis of the Relationship between Urbanization and Ecological Environment in Kunming}

\section{1) Analysis of urbanization and ecological environment index system}

According to Table II, in the process of urbanization, Kunming mainly focuses on the simultaneous construction of economic urbanization (0.261), social urbanization (0.262) and spatial urbanization $(0.271)$, for the proportion of population urbanization $(0.205)$ is relatively small. So we think its focus needs to be improved. Among them, the number of traffic mileage in towns in space urbanization has the highest parameter value $(0.070)$. The main reason is that the entire Yunnan Province is located in the plateau and mountainous areas, and the traffic is inconvenient. Therefore, the Kunming Municipal Government adheres to the development concept of "To be rich, to build roads first", and invests a lot of manpower, financial resources and material resources to build railways and highways. The transportation infrastructure such as the airport makes it an important transportation hub connecting the interior of Yunnan Province and the cities outside the province. Enhancing the economic strength of Kunming by improving the city's transportation capacity. In addition, the proportion of the secondary and tertiary industries in GDP and the proportion of urban population accounted for a relatively high proportion (0.069), which played a leading role in the overall urbanization level of Kunming. The number of urban parks, the number of public libraries and the total retail sales of social consumer goods are the lowest (0.063), which indicates that the urbanization process in Kunming is too dependent on the increase of urban economy and urban population, but ignores the people's need for "quality" in life in urbanization. With the urbanization process in Kunming, the ecological environment of Kunming is not optimistic. According to the PSR (pressure-state-response) model analysis, in Kunming: ecological pressure (0.403)> ecological state (0.313)> ecological response (0.284). The development of any city is inseparable from the support of natural resources, but the resources (water, gas, land, etc.) usually are limited. In addition, Kunming is located in the ecological fragile zone of alpine cold and drought, and people's production and living environment have strong ecology and vulnerability. However, Kunming has neglected the protection and construction of environmental quality (such as Dian Chi Lake Basin pollution) in the course of urbanization development, resulting in a large gap between ecological pressure and ecological response. It can be seen that ecological environmental protection and 
construction have become a part of the current development of Kunming city. In particular, the Kunming Municipal Government needs to propose corresponding improvement strategies in three aspects: afforestation area (0.054), total water resources $(0.061)$ and environmental protection investment $(0.061)$, thereby improving the quality of the ecological environment and making the eco-economic-social complex. The system does need to developing synchronously to avoid re-coordination and imbalance.

\section{2) Comprehensive evolution of urbanization and ecological environment}

As can be seen from Fig. 1, the urbanization level of Kunming has increased significantly in the past decade, especially during the period from 2006 to 2014. From the urbanization comprehensive score of 0.132 in 2007 to 0.892 in 2016 , the average annual increase rate is $21.5 \%$. As a provincial capital city, Kunming City clearly pointed out in the "Kunming City Master Plan (2011-2020)": "Kunming's development goal - trying to build Kunming into a gateway city facing China's southwest and an important regional national traffic Hubs and information hubs." Therefore, measures such as improving the transportation network, developing the industrial economy and increasing employment have promoted the development of urbanization in Kunming. However, from 2007 to 2016, Kunming's ecological environment comprehensive score showed a downward trend with the development of urbanization, from the 2006 urbanization comprehensive score (0.132) < ecological environment comprehensive score (0.424). After 2013, the ecological environment comprehensive score was overtaken by the urbanization comprehensive score: urbanization comprehensive score $(0.602)<$ eco-environment comprehensive score (0.526). By the end of 2016, the comprehensive score of the ecological environment has lagged behind the urbanization comprehensive score of 0.204 If the situation continues to develop, the gap between the two will increase. Once the urbanization level of Kunming exceeds the ecological threshold, it will face the danger of resources exhaustion. In addition, in the two periods of 2008-2009 and 2011-2013, the ecological environment itself is not optimistic, showing a downward trend. As far as the overall ecological environment of Kunming City is concerned, the overall score of the ecological environment fluctuates in the process of urbanization and cannot progress smoothly. Compared with other regions, the ecological environment of the entire Yunnan province has unique natural advantages: a wide variety of vegetation, surrounded by mountains and forests. How to give play to ecological advantages and avoid repeating the old road of "first pollution and development" has become a huge challenge in the urbanization process of Kunming. "It is necessary to have Jinshan Yinshan, but also green water and green mountains" is an important goal of Kunming and even the entire urbanization development of Yunnan Province. Therefore, how to maintain a steady increase in the comprehensive score of the ecological environment and shorten the comprehensive score gap between urbanization and ecological environment has become a key issue that must be faced and solved in the current urban development of Kunming.

\section{3) Time series characteristics of coupling coordination} between urbanization and ecological environment

Urbanization and ecological environment from a system of coupled interaction. Coupling degree and coupling coordination degree are important indicators to measure the coordinated development level of the system. According to the calculation results of coupling degree and coupling coordination degree (Fig. 1), the coupling degree and coupling coordination degree of urbanization and ecological environment in Kunming City showed an increasing trend during the research period, and experienced seven stages of moderate antagonism to mild coordination. First, the degree of coupling between the two systems increased from 0.201 in 2007 to 0.777 in 2016. This shows that the relationship between urbanization and ecological environment in Kunming is getting closer and closer, and the degree of interdependence is gradually deepening. Secondly, the degree of coupling coordination between the two systems increased from 0.236 in 2007 to 0.783 in 2016 . According to the corresponding classification criteria of coupling coordination degree, it can be known that the initial coordination between the two systems has evolved to the present coordination. The development reflects that Kunming gradually recognizes the importance of the ecological environment in the process of urbanization. In urban development, Kunming no longer attaches importance to the physical structure of "city" such as urban roads, building construction and infrastructure, but considers the intrinsic meaning of it. As a function of "city" in the social ecosystem, cities combine urbanization with the ecological environment to promote the development of the relationship between the two. Again, as can be seen from Fig. 1, Kunming entered the running-in phase in 2008 (coupling coordination degree of 0.327 ) (this phase lasted for eight years), explaining how to integrate urbanization and ecological environment into one, Kunming is still in the exploratory period and needs further consideration. Finally, the coupling coordination degree of Kunming City increased from 0.236 in 2007 to 0.783 in 2016 . During the decade, it experienced a mild antagonistic-run-in-light coordination development process. As far as the current urbanization and ecological environment of Kunming enters the coordination phase, this is related to the entire social environment of China. Since the reform and opening up, the rapid development of urbanization has also brought about various ecological problems, such as smog, water pollution, sharp decline in cultivated land, and acidification of soil. Therefore, many cities in China have successively proposed new goals for building an ecologically civilized city. Kunming has also become one of them. The "highland lakeside ecological livable city" has been positioned as a new target for urban development in Kunming.

\section{CONCLUSION}

Firstly, according to the situation of Kunming City, this paper constructs a set of index system to evaluate the relationship between urbanization and ecological environment. Using this method as a framework, the linear weighting method is used to calculate the comprehensive 
scores of the two systems over a decade, and then the coupling degree model is constructed. By using the coupling coordination degree model, we analyzed the current status and dynamic evolution process of urbanization and ecological environment development in Kunming in the past 10 years from the perspective of time series, using mathematical statistics methods and models for urbanization and ecological environment and two systems. The quantitative coordination degree has been quantitatively measured, and the following conclusions are drawn: i) During the past 10 years, Kunming's economic urbanization, social urbanization and spatial urbanization have basically developed simultaneously, but the urbanization of population needs further improvement; ii) The urbanization horizontal rises linearly, the ecological environment fluctuates and falls; iii) The evolution of the degree of coupling between the two systems of urbanization and ecological environment goes through three stages: antagonism, running-in and coordination. At the same time, the shortcoming of this paper is just to focus on the study of Kunming's time series, and the lack of spatial analysis of the coordination between urbanization and ecological environment needs to be further more.

\section{CONFLICT OF INTEREST}

The whole authors declare no conflict of interest about the paper.

\section{AUTHOR CONTRIBUTIONS}

Author Xia Chunhong as the first author in this paper is the responsible to anlyse datas and writes paper. Author Li Yan as corresponding author approved the final version. Author Li Ruiliang collected the datas.

\section{REFERENCES}

[1] CSB, China Statistical Yearbook, China Statistics Press, Beijing, 2016.

[2] H. Tomorrow, A Road to Peace That Leads to Real Reform, The Commercial Press, Beijing, 2000.

[3] R. C. D'Arge and K. C. Kogiku, "Ecomonic growth and the environment," The Review of Economic Studies, vol. 40, pp. 61-77, 1973.

[4] H. Iwata et al., "Empirical study on the environmental Kuznetscurve for $\mathrm{CO}_{2}$ in France: The role of nuclear energy," Energy Policy, vol. 38, pp. 4057-4063, 2010.

[5] Z. J. Lin, "Ecological urbanism in East Asia: A comparative assessment of two eco-cities in Japan and China," Landscape and Urban Planning, vol. 179, pp. 90-102, 2018.

[6] J. Ochoa et al., "Learning from best practices in sustainable urbanization," Habitat International, vol. 789, pp. 83-95, 2018.

[7] X. R. Wang, Urban Ecology, Fudan University Press, Shanghai, China, 2013.

[8] K. M. Zhang et al., Low Carbon Development Theory, China Environmental Science Press, Beijing, China, 2009.

[9] J. Xu et al., "A review of the research on urban ecological civilization construction in China," Economic Geography, vol. 34, pp. 137-185, 2014.

[10] Q. J. Shen, "Resilience thinking and urban ecological planning," Ecological Planning / Urban and Rural Park, vol. 6, pp. 1-7, 2018.

[11] J. C. Huang and C. L. Fang, "Interaction and regularity analysis of urbanization and ecological environment interaction," Geographical Research, vol. 22, pp. 211-220, 2003.

[12] Y. B. Liu and X. F. Song, "Coupling mode and discrimination of urbanization and ecological environment," Geographical Science, vol. 25, pp. 408-414, 2005
[13] C. L. Fang and Y. M Yang, "The basic law of the interaction system between urbanization and ecological environment," Arid Land Geography, vol. 29, pp. 1-8, 2006.

[14] B. Qiao et al., "Research progress and prospect of interaction process between urbanization and eco-environment in arid areas," Arid Land Geography, vol. 29, pp. 1-8, 2006.

[15] Y. M. Guo, "Evaluation of the ecological civilization construction of Chengdu-Chongqing urban agglomeration," Master thesis, Chengdu University of Technology, Chengdu, Sichuan, China, 2017.

[16] F. Wang et al., "Quantitative analysis of Xinjiang tourism - New urbanization-ecological environment coordination relationship based on coupling model," Journal of Natural Science of Hunan Normal University, vol. 56, pp. 78-82, 2018

[17] H, W. Zheng and Y. Z. Liu, "Ugly establishment, evaluation of coordinated development of urban land intensive use and ecological environment in China," Soil and Water Conservation Newsletter, vol 1, pp. 46-52, 2012

[18] N. Liu et al., "Examing the coordination between urbanization and eco-environment using coupling and spatial analyses: A case study in China," Ecological Indicators, vol. 93, pp. 1163-1175, 2018.

[19] H. D. Huang, "A comparative study on the coordinated development of urbanization and ecological environment in China's urban agglomerations," Ecological Economy, vol. 32, pp. 45-48, 2014.

[20] G. H. Bi et al., "Coupling and coordinated development of provincial ecological civilization construction and urbanization in China," Economic Geography, vol. 110, pp. 352-377, 2017.

[21] J. J. Wang et al., "Preliminary study on the development of low carbon cities in Harbin based on DPSIR mode," Journal of Natural Science of Harbin Normal University, vol. 46, pp. 15-21, 2017.

[22] Z. Q. Yang and Z. M. Zhang, "Research on coordinated development of tourism economy and ecological environment based on coupling model - Taking Guilin city as an example," Journal of Northwest Forestry University, vol. 3, pp. 262-268, 2014.

Copyright $(\odot 2019$ by the authors. This is an open access article distributed under the Creative Commons Attribution License which permits unrestricted use, distribution, and reproduction in any medium, provided the original work is properly cited ( $\underline{\text { C BY 4.0) }}$.

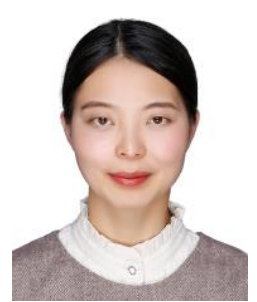

Chunhong Xia was born in Dali, Yunnan province, China on April 13, 1994. She got the master degree in 2020 in Yunnan University and her subject is urban management.

Ms. Xia has been working on the research of urban ecology and urban resilience. Meanwhile, she has published three papers about them. The titles are named "evaluation of ecological construction in Kunming using the DPSIR model. The study on the temporal and spatial characteristic of urban resilience in Yunnan ethic areas and study on the temporal and spatial characteristic of social-ecological resilience in China".

Ms. Xia has been award the best presentation in 2019 2nd International Conference on Geoinformatics and Data Analysis during March 15-17, 2019.

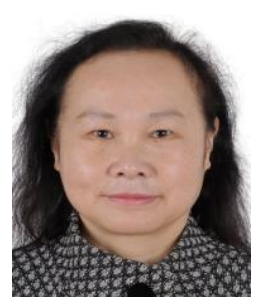

Yan Li was born in Chengdu, Sichuan Province, China on November 9, 1964. She got the Ph.D degree in 2018 in Yunnan University.

Associate Prof. Li has been working on the research of urban management. Meanwhile, she has published three papers about them. The titles are named "Evaluation of ecological construction in Kunming using the DPSIR model. The study on the temporal and spatial characteristic of urban resilience in Yunnan ethic areas. And Study on the temporal and spatial characteristic of social-ecological resilience in China".

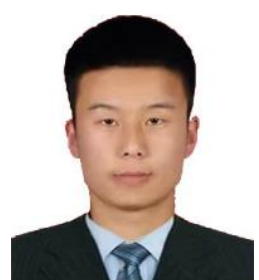

Ruiliang Li was born in Pingliang, Gansu Province, China on April 28, 1995. He got the master degree in 2021 in Yunnan University. His subject is urban management.

$\mathrm{Mr}$. Li has been working on the research of urban resilience and urban governance. Meanwhile, he has co-authored two papers about them. The titles are named "the study on the temporal and spatial characteristic of urban resilience in Yunnan ethic areas. And Study on the temporal and spatial characteristic of social-ecological resilience in China". 